\title{
Two-channel high-resolution quasi-monochromatic X-ray imager for Al and Ti plasma.
}

\author{
A. Do ${ }^{1,2}$, M. Briat ${ }^{1}$, S.D. Baton ${ }^{2}$, M. Krumrey ${ }^{3}$, L. Lecherbourg ${ }^{1}$, B. Loupias ${ }^{1}$, F. Pérez ${ }^{2}$, P. Renaudin ${ }^{1}$, \\ C. Rubbelynck ${ }^{1}, \mathrm{Ph}$. Troussel ${ }^{1}$ \\ ${ }^{1}$ Commissariat à l'Énergie Atomique, DAM-Île de France, BP 12, 91680 Bruyères-les-Châtel, France
}

2LULI-CNRS, École Polytechnique, CEA: Université Paris-Saclay ; UPMC Univ. Paris 06 : Sorbonne Universités, F-91128 Palaiseau cedex, France

${ }^{3}$ Physikalisch-Technische Bundesanstalt (PTB), Abbestr. 2-12, 10587 Berlin, Germany

\begin{abstract}
High-resolution, high-sensitivity X-ray imaging is a real challenge in High-Energy Density Plasma (HEDP) experiments. We present an improved design of the FUHRI (Fresnel Ultra High-Resolution Imager) instrument). Using an Ultra-High-Intensity (UHI) laser to generate hot and dense plasma in a small volume of an Al-Ti mixed target provides simultaneous imaging of both Al and Ti X-ray emission. Specifically, the $\mathrm{Al} \mathrm{He} \beta$ (or $\mathrm{Ly}_{\beta}$ ) and the $\mathrm{Ti} \mathrm{He}_{\alpha}$ lines are imaged with a resolution of $(2.7 \pm 0.3) \mu \mathrm{m}$ and $(5.5 \pm 0.3) \mu \mathrm{m}$, respectively. It features two transmission Fresnel phase zone plates fabricated on the same substrate, each associated with a multilayer mirror for spectral selection. Their spatial resolution has been measured on the PTB synchrotron radiation facility laboratory at BESSY II and on the EQUINOX laser facility. Results obtained on an UHI experiment highlight the difference of emission zone sizes between $\mathrm{Al}$ and $\mathrm{Ti}$ lines and the versatility of this instrument.
\end{abstract}

\section{Introduction}

Ultra-short laser pulses offer plasma conditions relevant to stellar opacities ${ }^{1}$, atomic physics in general ${ }^{2,3}$ and topics associated to inertial confinement fusion ${ }^{4}$. Experiments have been conducted on the LULI2000 laser facility (LULI, CNRS, Ecole Polytechnique) $)^{5}$ with an Ultra-High-Intensity (UHI) laser delivering $10^{17}$ to $10^{19} \mathrm{~W} \mathrm{~cm}^{-2}$ on target to $\mathrm{create}$ plasmas with temperatures of several $100 \mathrm{eV}$ and densities higher than $1 \mathrm{~g} . \mathrm{cm}^{-3}$, although only within a limited volume. These campaigns thus required a high-resolution monochromatic X-ray imager to characterize the plasma emission. FUHRI (Fresnel Ultra High-Resolution Imager) is an x-ray imager with a demonstrated resolution lower than $5 \mu$ for an energy bandwidth limited to $100 \mathrm{eV}$ centered around the $\mathrm{Al} \mathrm{He} /$ line at $1860 \mathrm{eV}$. It consists in a transmission Fresnel phase zone plate ${ }^{6}$ (FZP) associated to a multilayer (ML) mirror for spectral selection. The present article describes an advanced version, FUHRIx2, featuring two channels each based on the FUHRI principle. The first one, "Al", identical to the previous configuration, images the $\mathrm{Al} \mathrm{He} \beta$ line while the second, "Ti", images the He line of titanium at $4750 \mathrm{eV}$ with $100 \mathrm{eV}$ bandwidth.

The FUHRIx2 design is detailed in section II, followed by measurements of its FZP resolutions and ML mirror reflectance on a synchrotron facility (section III) and on a laser facility (section IV). Section V presents first results obtained on an UHI experiment.

\section{FUHRIx2 presentation}

The FUHRIx2 diagnostic is based on the high-resolution quasi-monochromatic x-ray imager FUHRI design presented in a previous paper ${ }^{7}$. The FUHRIx2 chip has two FZP engraved on the same silicon substrate for simultaneous imaging at two photon energies (Figure 1). Adding another channel to the diagnostic was a necessity for the UHI experiment as the experimental target were composed of a mixed material of Al and Ti. These two line self-emission image are characteristics of two different plasma temperatures and can be analyzed along with spectroscopic data. 
FZPs are focusing optics that can operate in the X-ray domain ${ }^{8}$. They consist of a circular transmission grating: alternating $\mathrm{N}$ concentric transparent and opaque zones ${ }^{9,10}$. The FZPs for FUHRIx2 are manufactured using an electroplating method by Applied Nanotools INC ${ }^{11}$. Their central area features a beam block (see Figure 1) to prevent direct emission ${ }^{7}$ (i.e. the $0^{\text {th }}$ order) to reach the detector.

One FZP was designed for the Al He $e_{\beta}$ line $(1860 \mathrm{eV})$ or Al Ly line $\left(2050 \mathrm{eV}\right.$, Table 1) and the other for the He $\mathrm{He}_{\alpha}$ line emission of $\mathrm{Ti}(\sim 4700 \mathrm{eV}$, Table 1). Both the central beam block surface and the surface outside the FZPs are covered by a $3 \mu \mathrm{m}$ electroplated gold layer to stop most of the hard x-rays. Both images are detected by a Princeton PI-MTE CCD camera.

The focal distance $\left(f_{\curlywedge}\right)$ of a FZP is directly linked to the wavelength of the $\mathrm{X}$-rays:

$$
f_{\lambda}=\frac{\lambda}{r_{1}^{2}} \text { (1) }
$$

where $r_{1}$ is the first zone radius and $\lambda$ the considered wavelength.

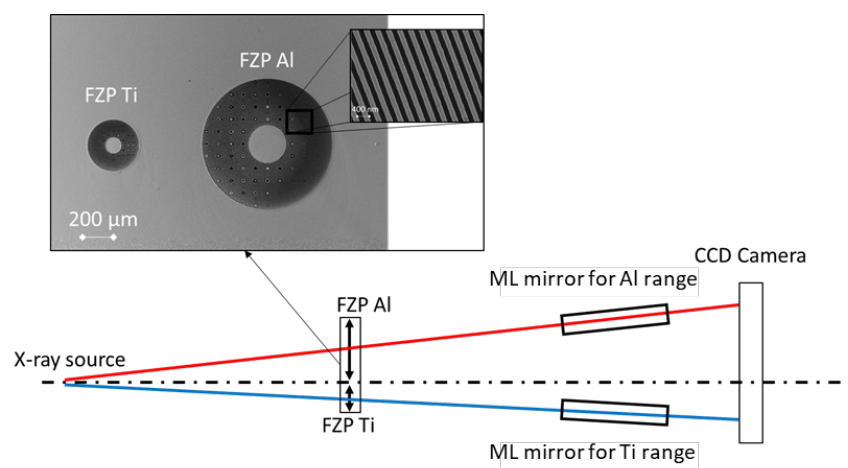

Figure 1 : FUHRIX2 setup. The two channels correspond to the Al and Ti emission focused on the CCD camera after spectral selection by ML mirrors. The top panel show a photograph of the substrate with the two FZPs.

Metrology studies were already performed to measure the AI FZP efficiency on a synchrotron radiation facility. To complete those data, additional resolution measurements have been conducted for the FZP both on a synchrotron radiation facility and on a laser facility (EQUINOX).

\begin{tabular}{|c|c|c|c|}
\hline & FZP type & $\mathrm{Al}(1860 \mathrm{eV})$ & $\mathrm{Ti}(4700 \mathrm{eV})$ \\
\hline \multirow{4}{*}{$\stackrel{0}{\underset{\sim}{N}}$} & Focal distance $\left(f_{\lambda}\right)$ & \multicolumn{2}{|c|}{$250 \mathrm{~mm}$} \\
\hline & Last zone width $\left(\Delta r_{n}\right)$ & \multicolumn{2}{|c|}{$(200 \pm 5) \mathrm{nm}$} \\
\hline & Diameter $(D)$ & $846 \mu \mathrm{m}$ & $330 \mu \mathrm{m}$ \\
\hline & Number of zones & 1058 & 412 \\
\hline \multirow{5}{*}{ 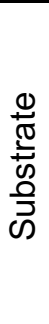 } & Material & \multicolumn{2}{|c|}{$\mathrm{Au}$} \\
\hline & Central stop & $\begin{array}{c}\mathrm{Au} \\
\text { (thickness: } 3 \mu \mathrm{m} \text {; diameter: } 240 \mu \mathrm{m} \text { ) }\end{array}$ & $\begin{array}{c}\mathrm{Au} \\
\text { (thickness: } 3 \mu \mathrm{m} \text {; diameter: } 110 \mu \mathrm{m} \text { ) }\end{array}$ \\
\hline & Zone thickness & \multicolumn{2}{|c|}{$620 \mathrm{~nm}$} \\
\hline & Membrane & \multicolumn{2}{|c|}{$\mathrm{Si}_{3} \mathrm{~N}_{4}(100 \mathrm{~nm}$ thickness) } \\
\hline & Support & \multicolumn{2}{|c|}{ Si wafer $(10 \mathrm{~mm} \times 10 \mathrm{~mm} \times 0,2 \mathrm{~mm})$} \\
\hline
\end{tabular}

Table 1: FZPs characteristics

\section{Metrology on a synchrotron radiation facility}

The metrology of the components was performed at the Four-Crystal Monochromator (FCM) beamline in the Physikalisch-Technische Bundesanstalt (PTB) laboratory at the synchrotron radiation facility Bessy $\mathrm{II}^{1}$. The accessible photon energy range of this beamline extends from $1.75 \mathrm{keV}$ to $11 \mathrm{keV}$ using either $\mathrm{Si}$ or InSb crystals as monochromator. The zone plates were placed in an ultra-high-vacuum reflectometer ${ }^{2}$, which provides $0.001^{\circ}$ angular resolution for the sample and the detector. 


\section{FZP spatial resolution}

\section{Resolution measurement method}

The resolution of the FZP was measured with the knife edge method (cf. Figure 2). The monochromatic beam was collimated to have a size of $0.5 \mathrm{~mm} \times 0.5 \mathrm{~mm}$. First, the piezo-blade covers all the synchrotron beam signal. Then it is removed gradually (Figure 2), with a step size of $1 \mu \mathrm{m}$ or $0.2 \mu \mathrm{m}$, to reveal the focal spot until it totally gets out of the beam. The signal was recorded using an $8 \mathrm{~mm}$ diameter photodiode.

The resolution is obtained as the full width at half maximum (FWHM) of the derivative of the measured signal as a function of blade position. An example of such a result for the AI FZP of FUHRIx2 is presented on Figure 3.

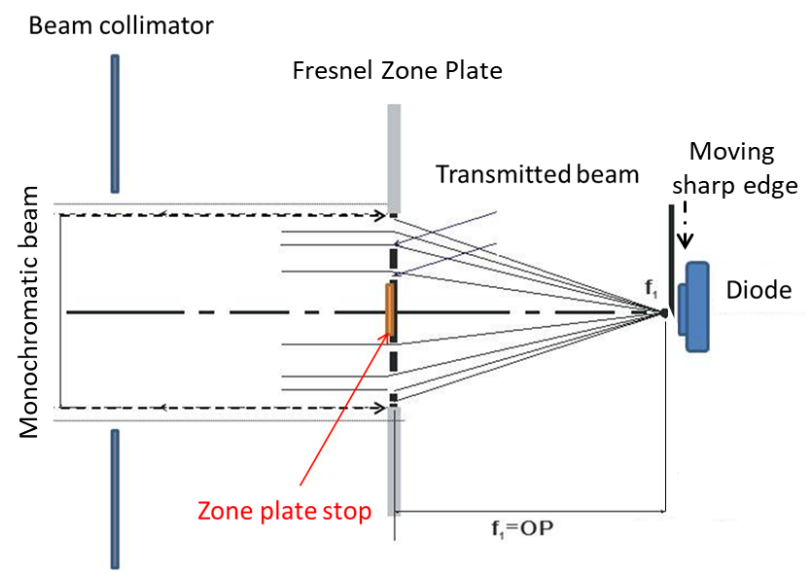

Figure 2: Knife edge method

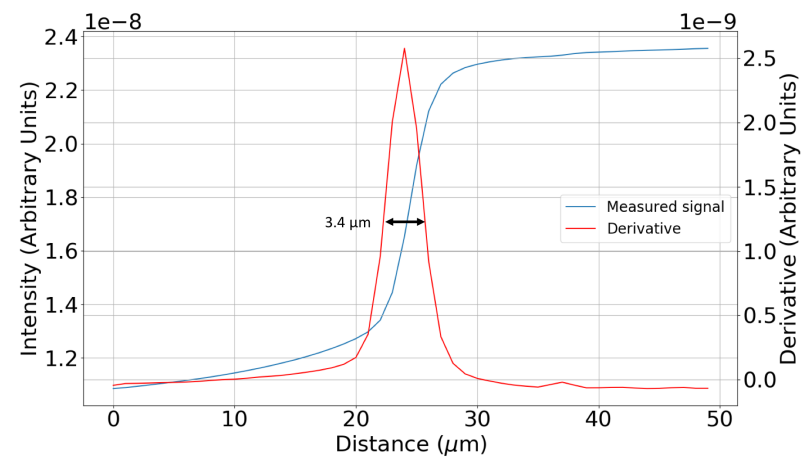

Figure 3: Example of a spatial resolution measurement for the AI FZP of FUHRIx2 using the sharp edge method for a FZP-blade distance of $253 \mathrm{~mm}$, an energy of $1850 \mathrm{eV}$.

\section{Resolution measurement of FUHRIx 2 FZPS}

Figure 4-a shows the results for the Al FZP at a photon energy of $1852 \mathrm{eV}$. At a FZP-blade distance of $253 \mathrm{~mm}$, a minimum FWHM of $(3.4 \pm 0.3) \mu \mathrm{m}$ was achieved. In Figure-b the resolution measurement at different energies for the $\mathrm{Al}$ FZP are shown for a FZP-blade distance of $253 \mathrm{~mm}$. A $\pm 5 \mathrm{eV}$ variation of the energy induces a spatial resolution variation of a factor $\mathrm{x} 2$.

(a)

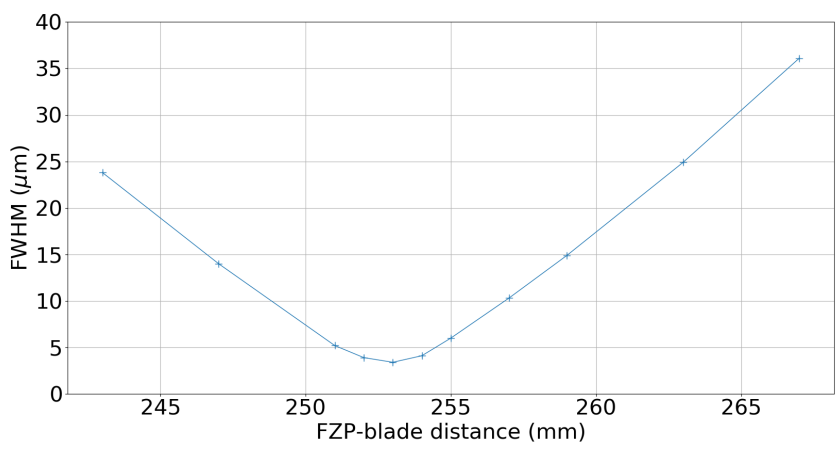

(b)

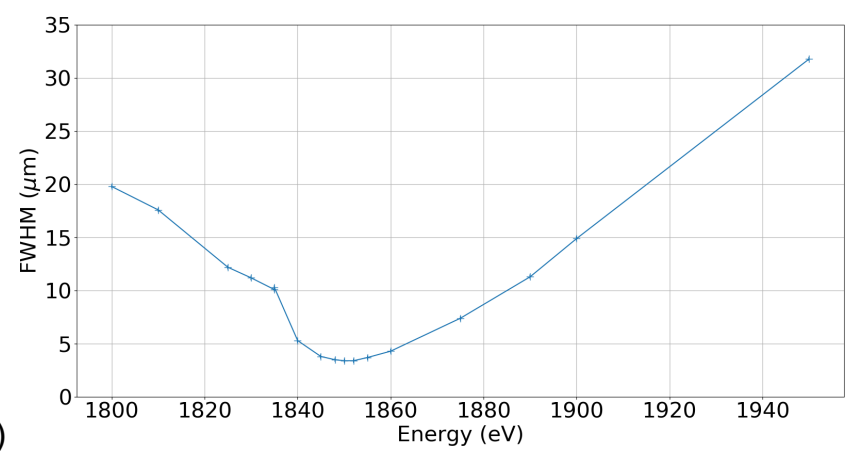


Figure 4: (a) Al FZP resolution as a function of the FZP-blade distance for a photon energy of $1852 \mathrm{eV}$. (b) Al FZP resolution as a function of the photon energy at best focus for $1852 \mathrm{eV}$.

As both FZP were placed on the same support the resolution of the Ti FZP was also measured at $253 \mathrm{~mm}$ distance from the blade. Resolution of $5 \mu \mathrm{m}$ was obtained for the Ti FZP and remain stable within at least $\pm 25 \mathrm{eV}$ energy range around the energy of $4700 \mathrm{eV}$.

\section{ML Mirror reflectivity measurements}

The components of the multilayer mirrors were deposited by Axo-Dresden ${ }^{12}$. The thickness of each layer can be calculated from the X-ray reflective peaks according the Bragg formula.

The "Al" ML mirror consists of 50 pairs of $\mathrm{Pd} / \mathrm{B}_{4} \mathrm{C}$ layers $(2.6 \mathrm{~nm} / 2.5 \mathrm{~nm})$. The measured and calculated reflectivity curves are compared on Figure 5-a using a Debye Waller roughness of $0.65 \mathrm{~nm}$.

The "Ti" ML mirror is made of 60 stacks of Mo/Si periodical layers. The measured reflectance versus photon energy at $1.975^{\circ}$ grazing angle is shown on Figure 5-b. The theoretical reflectance (dashed curve) was calculated by the XRV software ${ }^{16,17}$, considering a $0.6 \mathrm{~nm}$ mean interface substrate layer. From the fitting of the experimental results, we obtain the interface roughness of $0.4 \mathrm{~nm}$.

(a)

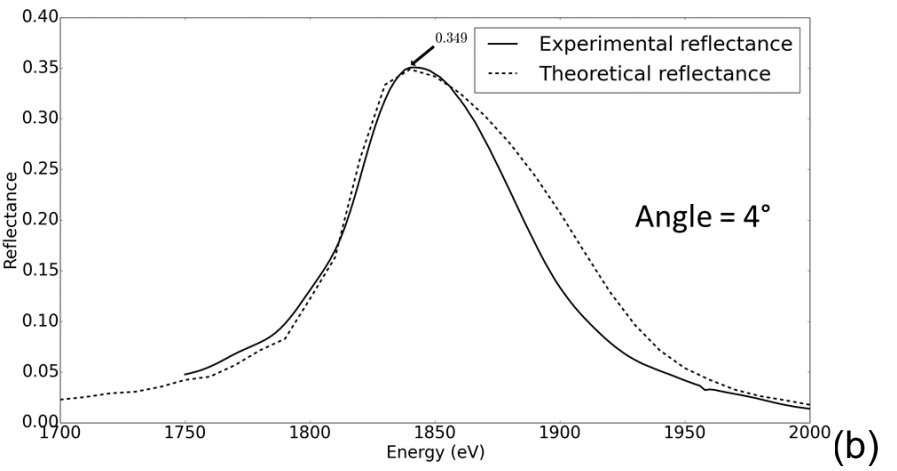

Figure 5: (a) "Al" FZP ML mirror reflectance. (b) "Ti" FZP ML mirror reflectance.

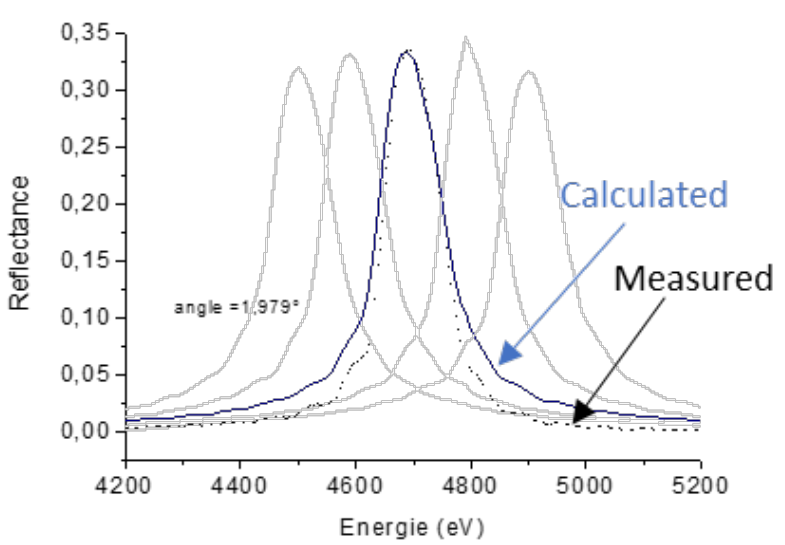

\section{Metrology on a laser facility}

The EQUINOX laser facility ${ }^{13,14}$ features a $800 \mathrm{~nm}$-wavelength Ti:sapphire laser producing $0.3 \mathrm{~J}$ pulses, focused by an off-axis parabola. The laser pulse duration can be adjusted from $80 \mathrm{fs}$ to $30 \mathrm{ps}$. As the focal spot diameter is about $50 \mu \mathrm{m}$, the irradiance on a flat solid target varies between $10^{14}$ and $10^{17} \mathrm{~W} / \mathrm{cm}^{2}$, and mostly produces X-rays in the 100 $\mathrm{eV}-2 \mathrm{keV}$ range. The laser can operate at $10 \mathrm{~Hz}$ for signal accumulation.

The experimental set-up used was the same as that described in ref. [7] and is shown on Figure 6. Our X-ray source is created by irradiating a large Ti or Al foil target with the laser beam. We placed a gold grid $(10 \mu \mathrm{m} / 40 \mu \mathrm{m}$ periods $)$ at a distance $d$ from the source, the FZP at a distance $p$ from the grid and a CCD camera at a distance $q$ from the FZP.

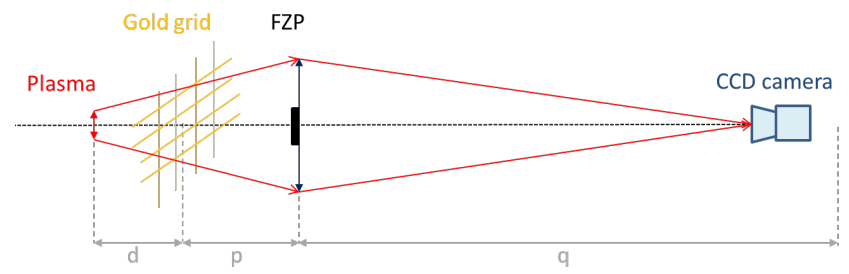

Figure 6: Generic experimental set-up

Using a ML mirror in combination with the FZP selects a specific photon energy band and the corresponding focal distance (Eq. 1). However, in this experiment the geometrical constraints did not allow us to use a ML mirror, this absence caused the whole spectrum to be integrated, thus degrading the resolution significantly. The following 
resolution measurements must thus be considered as an upper limit. For an optimal result in this situation, the best focusing distance is that of the average energy across the whole spectrum. In the Al case, this average is at $1630 \mathrm{eV}$, leading to a $222 \mathrm{~mm}$ focal distance. For the Ti spectrum, with our experimental conditions, the average is close to the Hea lines (4726.7 eV and $4749.2 \mathrm{eV}$ ) thus the focal distance is $250 \mathrm{~mm}$ (see Table 1).

For each configuration we calculated the $\mathrm{p}$ distance with the thin lens formula:

$$
\frac{1}{f}=\frac{1}{p}+\frac{1}{q}(2)
$$

1. Resolution measurements

\begin{tabular}{c|lllllllll} 
Target & $\begin{array}{l}\text { Number } \\
\text { of shots }\end{array}$ & Filters & $d(\mathrm{~mm})$ & $p(\mathrm{~mm})$ & $q(\mathrm{~mm})$ & $q / p$ & $q /(d+p)$ & Resolution & Contrast \\
Al (a) & 100 & $\begin{array}{l}\text { MylarAl }(2 \mu \mathrm{m} / 0.15 \mu \mathrm{m}) \\
\mathrm{Be}(10 \mu \mathrm{m})\end{array}$ & 185 & 243 & 2782 & 11.4 & 6.5 & $(5.4 \pm 1) \mu \mathrm{m}$ & $24 \%$ \\
$\operatorname{Ti}(\mathrm{b})$ & $100 \quad \begin{array}{l}\mathrm{Ti}(8 \mu \mathrm{m}) \\
\mathrm{Be}(10 \mu \mathrm{m})\end{array}$ & 153.3 & 274.7 & 2782 & 10.1 & 6.5 & $(7.5 \pm 1) \mu \mathrm{m}$ & $20 \%$
\end{tabular}

Table 2: Resolution measurements experiment parameters for the Al and Ti configurations.

The signal is collected with a Princeton CCD camera, with a pixel size of $13.5 \mu \mathrm{m} \times 13.5 \mu \mathrm{m}$ by accumulating 100 shots (Figure 7 ).

(a)
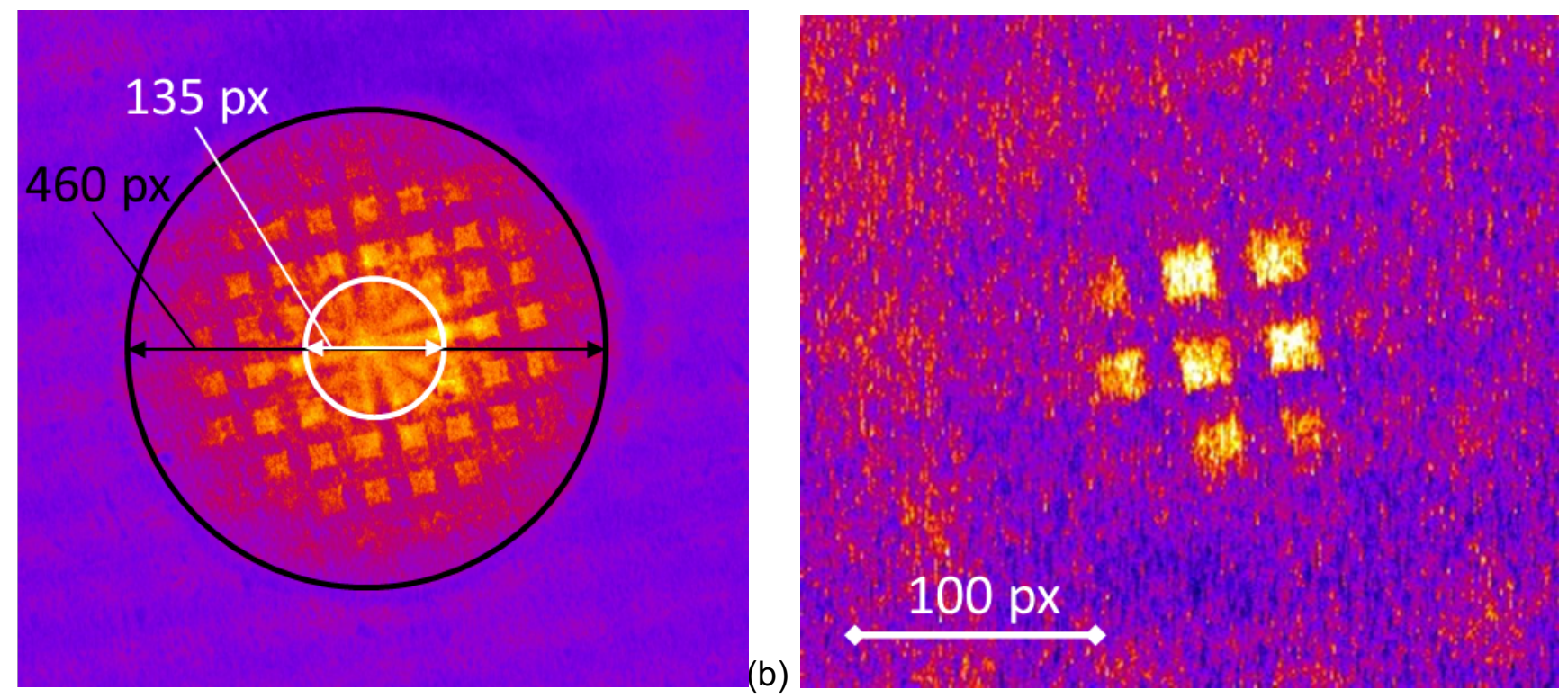

Figure 7: FUHRIx2 grid radiography image realized at the EQUINOX facility for the (a) Al and (b) Ti given in Table 2.

Note that, for the Al configuration (Figure 7-a), the area inside the white circle is strongly affected by the FZP beam stop. The grid is located relatively far from the plasma to allow a large field of view, but this reduce the photon flux and add diffractions effect on the beam stop, creating the "converging" effect in the white circle of Figure 7-a. The average value of the resolution measured using the sharp edge method is $(5.4 \pm 1) \mu \mathrm{m}$ with a mean $24 \%$ contrast defined as: (highest signal - lowest signal)/(highest signal + lowest signal). To estimate the effect of an error made on the FZP position, to reproduce this situation we did two resolutions measurement with the grid out of focus $(-4 \mathrm{~mm}$ and $+3 \mathrm{~mm})$. In both case, we measured an average of $(7.3 \pm 1) \mu \mathrm{m}$ resolution with a $26 \%$ contrast.

For the Ti configuration, the resolution measured here is $(7.5 \pm 1) \mu \mathrm{m}$ with a $20 \%$ contrast. This suggests that the quality of the Ti FZP is slightly lower than the Al, which confirms the measurement made in Part. III.1. However, the value differences Part III. and Part IV. are likely influenced by the non-monochromaticity of the x-ray source. As in the latter measurement there are no spectral selection, all the energies are being detected on the CCD camera adding more background and blurring to our signal.

\section{FUHRIx2 results on a UHI experiment}

We implemented FUHRIx2 during a laser-plasma interaction experiment on the LULI2000 facility. When an UHI laser pulse is focused on a thin target $(<10 \mu \mathrm{m})$, the suprathermal electrons generate a return current which heats a 
small volume isochorically ${ }^{15}$. One objective of the experiment was to measure the spatial distribution of $x$-ray emission caused by this hot plasma. These emission lines are temperature dependent, thus providing some insight on the spatial temperature distribution.

The laser delivered pulses from 10 to $15 \mathrm{~J}$ in 1.3 ps at a wavelength of $526 \mathrm{~nm}$ focused on $\mathrm{CH} / \mathrm{Ti}-\mathrm{Al} / \mathrm{CH}$ layered targets ( $\mathrm{Al}$ and $\mathrm{Ti}$ are mixed) with an intensity of $1.610^{19} \mathrm{~W} . \mathrm{cm}^{-2}$. FUHRIx2 was used to investigate the spatial temperature distribution of the aluminum and titanium layer's heated region. The thermal X-ray emission was focused by the FZPs, and the ML mirror, placed in front of the CCD camera, selected the He-like emission from Al and Ti. FUHRIX2 was placed at $22.5^{\circ}$ from the target rear normal. The target-FZPs distance was $p=266.2 \mathrm{~mm}$ and the detector-FZPs distance $q=4100 \mathrm{~mm}$ corresponding to a magnification around 15.2 and a collection solid angle of 9 $10^{-6} \mathrm{sr}$. The "Al" ML mirror angle was $\theta=4^{\circ}$ and the "Ti" ML mirror angle was $\theta=2^{\circ}$. Two configurations were used for FUHRIx2. The first was optimized for 2 channels at $1850 \mathrm{eV}(\mathrm{Al} \mathrm{He})$ and $4700 \mathrm{eV}\left(\mathrm{Ti} \mathrm{He}_{\alpha}\right)$, while the second was optimized for $2050 \mathrm{eV}$ only $\left(\mathrm{Al} \mathrm{H} \mathrm{H}_{\beta}\right.$ ). The parameters are summarized in Table 3, and the transmission of FUHRIx2 for two Al configurations are presented on Figure 8 with integrated spectra.

\begin{tabular}{l|lllll} 
Target & Filters & $p(\mathrm{~mm})$ & $q(\mathrm{~mm})$ & $q / p$ & $\Theta$ \\
\hline $\mathrm{CH} / \mathrm{Ti}-\mathrm{Al} / \mathrm{CH}$ & $\mathrm{PP}(10 \mu \mathrm{m})$ & 266.2 & 4100 & 15.2 & $4^{\circ}(\mathrm{Al}) / 2^{\circ}(\mathrm{Ti})$ \\
& $\operatorname{Be}(10 \mu \mathrm{m})$ & & & & $\operatorname{Or} 3.65^{\circ}(\mathrm{Al}) / 2^{\circ}(\mathrm{Ti})$
\end{tabular}

Table 3: Experiment setup parameters.

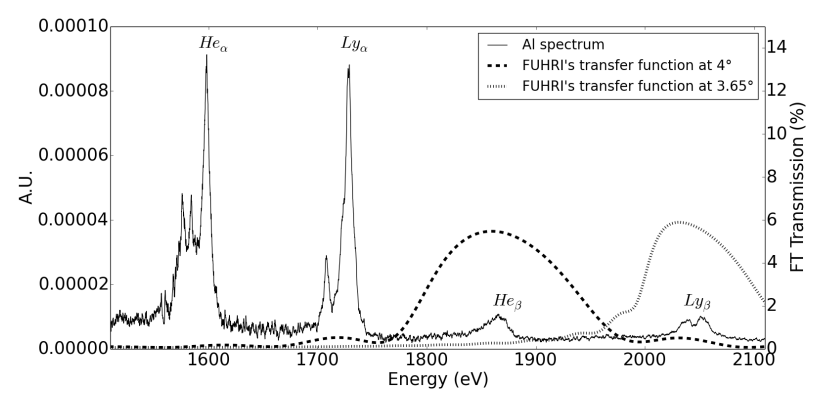

Figure 8: FUHRIx2 Al total transmission for two different mirror angles, superimposed with a typical X-ray spectrum from an UHI experiment.

Unfortunately, we were not able to measure the resolution of each FUHRIx2 channel, we can only give an estimation of the resolution based on our previous paper ${ }^{7}$ using FZPs resolution measurement on synchrotron (Part. III) and on a laser facility (Part. IV). Based on the measured resolution of the CCD camera $\left(\sigma_{C C D}=[2.3 \pm 0.15] \mu \mathrm{m}\right)$ and the resolution of the FZP $\left(\sigma_{F P Z P-A l}=[1.5 \pm 0.3] \mu \mathrm{m}\right.$ and $\left.\sigma_{F P Z P-T i}=[5.0 \pm 0.3] \mu \mathrm{m}\right)$, we obtain a total resolution for each channel of: $\sigma_{\text {Tot-Al }}=[2.7 \pm 0.3] \mu \mathrm{m}$ and $\sigma_{T o t-T i}=[5.5 \pm 0.3] \mu \mathrm{m}$.

An example of images obtained with FUHRIx2 is presented on Figure 9-a. We can see the "Ti" image on the left side and the "Al" image on the right side as well as a small part of the direct beam. 


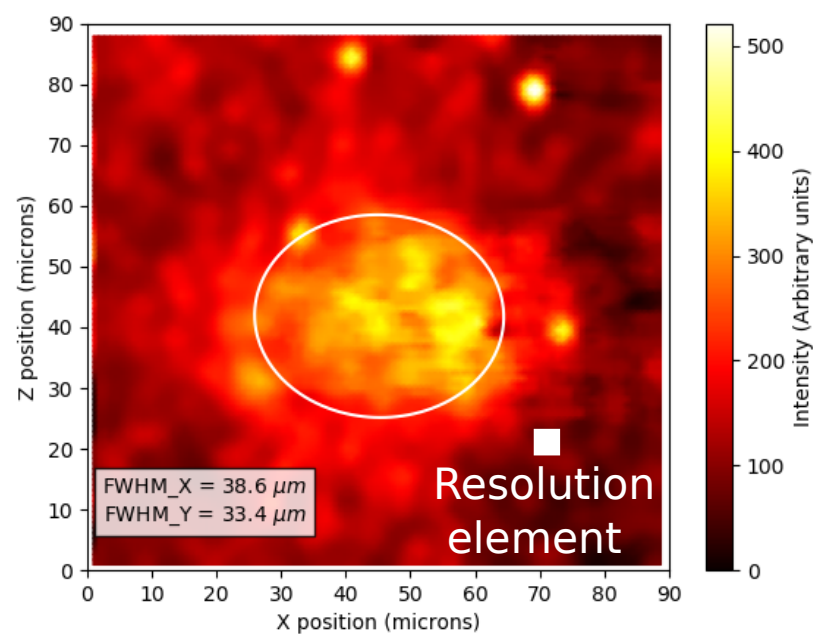

(a)

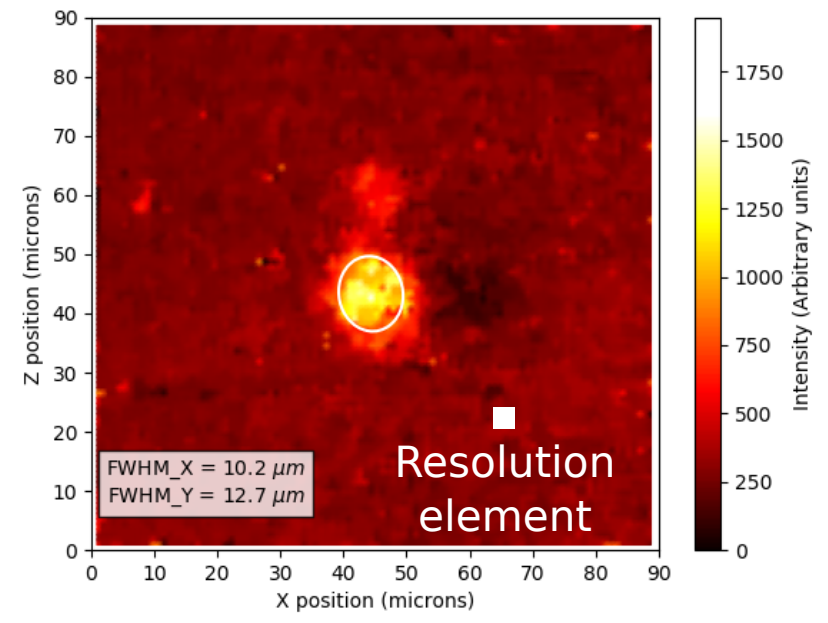

(b)

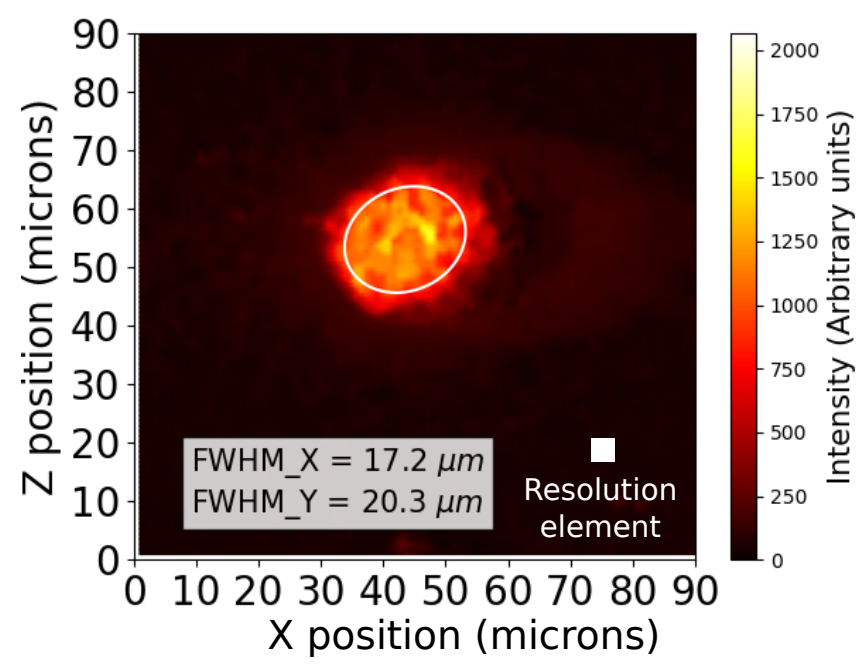

(c)

Figure 9: Sample image of FUHRIx2 for a $1.610^{19} \mathrm{~W} . \mathrm{cm}^{-2}$ intensity shot on a mixed target of $\mathrm{CH} / \mathrm{Al}-\mathrm{Ti} / \mathrm{CH}$ for (a) the Al FZP at $1850 \mathrm{eV}\left(\mathrm{He}_{\beta}\right),(\mathrm{b})$ the Ti FZP at $4700 \mathrm{eV}\left(\mathrm{He}_{\alpha}\right)$, and (c) the Al FZP at $2050 \mathrm{eV}\left(\mathrm{Ly}_{\beta}\right)$.

To compare different lines, we analyzed shots on $\mathrm{CH} / \mathrm{Al}-\mathrm{Ti} / \mathrm{CH}$ with the same laser energy $(\sim 16 \mathrm{~J})$ and pulse duration. Sample images for each energy are presented on Figure 9-abc. Note that the two images on figure 9bc are from the same shot. The FWHM was estimated using a 2D-Gaussian fit of the images and the results are sown on Table 4. Here we are looking at the same plasma at different energy. For a set of plasma conditions, each emission lines of $\mathrm{Al}$ and $\mathrm{Ti}$ will have a specific emission zone size and brightness. Thus, we will be able to compare the size and the absolute emission measured with FUHRIx2 with theoretical calculations to verify our emission models. Detailed analysis of all the experimental data will be conducted in another paper. What we can observe here is that the emission area for each $\mathrm{X}$-ray line is smaller for higher $\mathrm{X}$-ray energies. This match corresponds to the heat propagation inside the target: lower temperatures (i.e. lower $\mathrm{X}$-ray energies) are found far from the heat source.

\begin{tabular}{l|lll} 
Lines & $\boldsymbol{A} \mathbf{H} \mathbf{H e}_{\boldsymbol{\beta}}$ & $\boldsymbol{A} \mathbf{L} \boldsymbol{y}_{\boldsymbol{\beta}}$ & $\mathbf{T i ~ H e}_{\boldsymbol{\alpha}}$ \\
\hline Resolution $(\mu \mathrm{m})$ & $(2.7 \pm 0.3)$ & $(2.7 \pm 0.3)$ & $(5.5 \pm 0.3)$ \\
E $_{\text {FUHRI }} \pm 50 \mathrm{eV}$ & 1850 & 2050 & 4700 \\
FWHM $(\mu \mathrm{m})$ & $30-40$ & $16-25$ & $11-15$
\end{tabular}

Table 4: Emission zone size for each energy.

\section{Conclusions}


We improved our previous high-resolution X-ray imager by adding an additional measurement channel allowing us to capture simultaneously the size of the emission zone of two different $x$-ray emission lines with resolutions of $(3.4 \pm 0.3) \mu \mathrm{m}$ for the Al lines and of $(5.5 \pm 0.3) \mu \mathrm{m}$ for the Ti line. We proved the versatility of our system by changing the observed energy of one of our channels.

The investigation of chromatism effect on diagnostic performances will be pursued in a future article using $\mathrm{x}$-ray tracing and wave propagation methods.

\section{ACKNOWLEDGMENTS}

The authors acknowledge the LULI2000 team, the LULI target lab, as well as Levent Cibik and Swenja Schreiber (both PTB) for their help during the experiments as well as Laboratoire de Photonique et de Nanostructures (LPNCNRS, Marcoussis, France) lab team for their help in imaging FZP with a scanning electron microscope.

\section{References}

${ }^{1}$ M. Krumrey and G. Ulm,Nucl. Instr. and Meth. A 467-468, 1175 - 1178 (2001)

${ }^{2}$ D. Fuchs, M. Krumrey, P. Müller, F. Scholze and G. Ulm, Rev. Sci. Instrum. 66, 2248 - 2250 (1995)

${ }^{3}$ C. Blancard, Ph. Cossé, G. Faussurier, The Astrophysical Journal, Volume 745, Issue 1, article id. 10, 7 pp. (2012).

${ }^{4}$ M. Tabak, J. Hammer, M. E. Glinsky, et al., 1994. Physics of Plasmas, vol. 1 p. 1626-1634.

${ }^{5}$ LULI2000. LULI. www.luli.polytechnique.fr/accueil/les-installations/luli2000.

${ }^{6}$ J. Kirz, J. Opt. Soc. Am. 64, 301-309 (1974).

${ }^{7}$ A. Do, Ph. Troussel et Al., Rev Sci Instrum. 2017 Jan.88(1): 013701.

${ }^{8}$ F A. Jenkins, H.E. White. Fundamentals of Optics. Chap. 18, Frensel Diffraction. s.I. : McGraw-Hill Book Compagny (1957).

${ }^{9} \mathrm{~K}$. Kamiya, Science of light, pp. Vol. 12, No. 2, p. 35-49 (1963).

${ }^{10}$ G. Cauchon, M. Pichet-Thomasset, R. Sauneuf, P. Dhez, M. Idir, M. Ollivier, Ph. Troussel, J.-Y. Boutin and J.-P. Le Breton, Rev. Sci. Instrum., Vol. 69, 3186 (1998).

${ }^{11}$ www.appliednt.com

${ }^{12} \mathrm{http}: / /$ www.axo-dresden.de/

${ }^{13}$ J. P. LeBreton, E. Alozy, J. Y. Boutin, A. Duval, S. Gary, D. Gontier, S. Jasmin, M. Naudy, C. Reverdin, R. Rosch et al., Rev. Sci. Instrum. 77, 10F530 (2006).

${ }^{14}$ Ch. Reverdin, M. Paurisse, T. Caillaud, P. Combis, A. Duval, D. Gontier, D. Husson, Ch. Rubbelynck, and C. Zuber, Rev. Sci. Instrum. 79, 10E932 (2008).

${ }^{15}$ V. Dervieux, B. Loupias, S. Baton, et al. 12-17, 2015, HEDP, Vol. 16.

${ }^{16} \mathrm{~T}$. Moreno, Software X-ray Vision applied by Caminotec, Paris, France

${ }^{17}$ L. G. Parratt, Phys. Rev. 95, 2 (1954). 